Background and aims We tested the hypothesis that moderate permissive hypercapnia (PHC) results in less lung injury than mild hypercapnia (MHC) and therefore may reduce the concentration of proinflammatory cytokines and acid sphingomyelinase (ASMase) in tracheal aspirates.

Methods Preterm infants (birthweight 400-1000 g, gestational age 23 0/7-28 6/7 weeks) requiring mechanical ventilation within the first $24 \mathrm{~h}$ after birth, were randomised to receive either PHC $\left(\mathrm{PaCO}_{2}\right.$ target area starting with 55-65 $\mathrm{mm} \mathrm{Hg}$ at day 1 to $65-75 \mathrm{~mm} \mathrm{Hg}$ at day 7$)$ or $\mathrm{MHC}\left(\mathrm{PaCO}_{2}\right.$ target area starting with $40-50 \mathrm{~mm} \mathrm{Hg}$ at day 1 to $50-60 \mathrm{~mm} \mathrm{Hg}$ at day $7)$. Tracheal aspirates were collected and analysed for IL- $1 \beta$, IL6, IL-8, IL-10, MIP- $1 \alpha, \mathrm{LTB}_{4}$, TGF- $\beta_{1}$, NPY, albumin, nitrate, ASMase and the secretory component for IgA. The primary endpoint BPD or death was determined at a postmenstrual age of 36 weeks \pm 1 day.

Results 71 infants were enrolled, 35 received PHC and 36 $\mathrm{MHC}$. Analyses of variance for the main effect of the $\mathrm{PaCO}_{2}$ targets did not detect significant differences: IL-1 $\beta$ ( $\mathrm{p}=0,42)$, IL-6 $(\mathrm{p}=0,44)$, IL-8 $(\mathrm{p}=0,91)$, IL-10 $(\mathrm{p}=0,87)$, MIP-1 $\alpha(\mathrm{p}=$ $0,34), \mathrm{LTB}_{4}(\mathrm{p}=0,87)$, TGF- $\beta_{1}(\mathrm{p}=0,26)$, NPY $(\mathrm{p}=0,47)$, albumin $(\mathrm{p}=0,63)$, nitrate $(\mathrm{p}=0,73)$, ASMase $(\mathrm{p}=0,25)$. BPD or death occured in $9(26 \%)$ and in $10(28 \%)$ of infants receiving $\mathrm{PHC}$ or $\mathrm{MHC}$.

Conclusion PHC did not result in lower inflammatory activity than MHC in ventilated ELBWI.

\section{PS-203 PRE- AND POST-NCPAP VENTILATION PLASMA CYTOKINE LEVELS IN PRETERM NEWBORN INFANTS WITH EARLY RESPIRATORY DISTRESS}

${ }^{1} \mathrm{CG}$ Carvalho, ${ }^{1} \mathrm{RS}$ Procianoy, ${ }^{2} \mathrm{EC}$ Neto, ${ }^{1} \mathrm{RC}$ Silveira. ${ }^{1}$ Neonatology, HCPA-UFRGS, Porto Alegre - Brazil, Brazil; ${ }^{2}$ Neonatology, Laboratorio Nobel, Porto Alegre - Brazil, Brazil

10.1136/archdischild-2014-307384.501

Introduction Mechanical ventilation (MV) induces expression of pro-inflammatory cytokines. Early nasal continuous positive airway pressure (nCPAP) seems to prevent ventilator-induced lung injury - and these effects have not been studied in humans.

Objective To evaluate plasma levels IL-1 $\beta$, IL-6, IL-8, IL-10, and TNF- $\alpha$ immediately before the start of nCPAP and $2 \mathrm{~h}$ later.

Methods Prospective cohort including preterm newborns with gestational age of 28-35 weeks admitted to a NICU for respiratory support. Newborns with malformations, congenital infections, sepsis, surfactant treatment, and receiving ventilatory support in the delivery room were excluded. Blood samples were collected right before and $2 \mathrm{~h}$ after the start of ventilation. Wilcoxon test was used for comparisons.

Results 23 preterm (mean weight $1850.65 \pm 403$ g; GA 32,36 $\pm 1,74$ weeks) were treated with nCPAP. A significant decrease in IL-6 levels was observed after $2 \mathrm{~h}$ of nCPAP. Of 15 newborns whose mothers received antenatal steroid, cytokine level was lower at the onset of nCPAP in all patients compared to those whose mothers didn't receive the treatment, but this effect was not sustained after $2 \mathrm{~h}$.

Conclusion nCPAP was associated with minimal release of proinflammatory cytokines and seems to play a less harmful role, which was enhanced by the use of antenatal steroids. As MV usually promotes a significant inflammatory response, the use of $\mathrm{nCPAP}$ as initial protective respiratory strategy for preterm with moderate respiratory distress should be supported.

\section{PS-204 \\ THE UTILITY OF N-TERMINAL PRO-BRAIN NATRIURETIC PEPTIDE IN ASSESSMENT OF RESPIRATORY DISTRESS IN TERM NEONATES}

${ }^{1} \mathrm{G}$ Markovic-Sovtic, ${ }^{2}$ J Kosutic, ${ }^{1} \mathrm{~B}$ Jankovic, ${ }^{3} \mathrm{~A}$ Sovtic, ${ }^{4} \mathrm{D}$ Bojanin, ${ }^{1} \mathrm{Z}$ Rakonjac. ${ }^{1}$ Department of Neonatology, Mother and Child Health Care Institute, Belgrade, Serbia; ${ }^{2}$ Department of Cardiology, Mother and Child Health Care Institute, Belgrade, Serbia; ${ }^{3}$ Department of Pulmonology, Mother and Child Health Care Institute, Belgrade, Serbia; ${ }^{4}$ Department of Laboratory Diagnostics, Mother and Child Health Care Institute, Belgrade, Serbia

\subsection{6/archdischild-2014-307384.502}

Background and aims The N-terminal pro-brain natriuretic peptide (NTpro-BNP) is used to differentiate congestive heart failure and lung disease in children and adults. The aim of our study was to determine its utility in the assessment of respiratory distress $(\mathrm{RD})$ in term neonates. We sought to find out whether it can distinguish cardiac from pulmonary aetiology of respiratory distress in term neonates.

Methods The NT pro-BNP level was determined in 60 neonates admitted for RD. They were further divided in two subgroups: 37 with congenital heart disease (CHD) and 23 with pulmonary disease. The control group consisted of 30 neonates with no signs of RD. Findings of auscultation, chest radiography, Silverman score and echocardiography were recorded for each patient. Blood samples for determining NT pro-BNP levels were obtained on admission, when blood sampling was indicated for the clinical management of the newborn.

Results The RD group, regardless of aetiology, showed significantly higher levels of NT- pro BNP than the control group $(\mathrm{p}<$ 0.001). Neonates with more severe RD had significantly higher level of NT-pro BNP ( $p=0.002)$. No significant difference was found between neonates with RD due to $\mathrm{CHD}$ and those with $\mathrm{RD}$ due to pulmonary disease.

Conclusions Term neonates with RD have significantly higher NT-pro BNP levels than healthy neonates. Higher level of NTpro-BNP indicates more severe RD. A single measurement of NT pro-BNP leve lcannot be used as the sole biomarker for distinguishing between cardiogenic and noncardiogenic aetiology of $\mathrm{RD}$ in term neonates.

\section{PS-205 INHALED NITRIC OXIDE INCREASES URINARY NITRIC OXIDE METABOLITES AND CGMP IN PREMATURE INFANTS: RELATIONSHIP TO PULMONARY OUTCOME}

${ }^{1} \mathrm{PL}$ Ballard, ${ }^{1} \mathrm{RL}$ Keller, ${ }^{2} \mathrm{DM}$ Black, ${ }^{3} \mathrm{DJ}$ Durand, ${ }^{3} \mathrm{JD}$ Merrill, ${ }^{4} \mathrm{EC}$ Eichenwald, ${ }^{5}$ WE Truog, ${ }^{6} \mathrm{MC}$ Mammel, ${ }^{7} \mathrm{R}$ Steinhorn, ${ }^{8} \mathrm{R}$ Ryan, ${ }^{9} \mathrm{SE}$ Courtney, ${ }^{1} \mathrm{RA}$ Ballard. ${ }^{1}$ Pediatrics, University of California San Francisco, San Francisco, USA; ${ }^{2}$ Epidemiology and Biostatistics, University of California San Francisco, San Francisco, USA; ${ }^{3}$ Pediatrics, Children's Hospital and Research Center, Oakland, USA; ${ }^{4}$ Pediatrics, University of Texas Medical School Houston, Houston, USA; ${ }^{5}$ Pediatrics, University of Missouri-Kansas City School of Medicine, Kansas City, USA; ${ }^{6}$ Pediatrics, Children's Hospital and Clinics of Minnesota, St. Paul, USA; ${ }^{7}$ Pediatrics, University of California Davis Children's Hospital, Sacramento, USA; ${ }^{8}$ Pediatrics, Medical University of South Carolina, Charleston, USA; ${ }^{9}$ Pediatrics, University of Arkansas for Medical Sciences, Little Rock, USA

\subsection{6/archdischild-2014-307384.503}

Background/aims Inhaled NO (iNO) has been tested for prevention of bronchopulmonary dysplasia in premature infants, however the role of cGMP is not known. We hypothesised that levels of NO metabolites (NOx) and cGMP in urine, as a noninvasive source for biospecimen collection, would reflect the dose of iNO and relate to pulmonary outcome. 